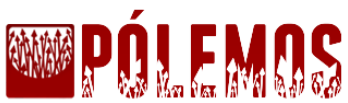

\section{NOÇÃO DE PROGRESSO NA CIÊNCIA EM KARL POPPER}

\author{
Evaldo Pereira de Rezende
}

Graduando em Filosofia pela Universidade de Brasília (UnB)

\section{RESUMO}

O presente texto visa discutir a noção de progresso na ciência em Karl Popper. Após uma breve exposição geral da orientação teórica dos positivistas lógicos, busca-se mostrar de que maneira Karl Popper participa desse debate, ao criticar uma das noções fundamentais da filosofia de Rudolf Carnap e do próprio Círculo de Viena, o princípio da verificabilidade como o critério de demarcação da ciência. Essa discussão converge para o debate acerca do tema central do artigo, a noção de progresso em Popper e, após a exposição sobre esse assunto, procura-se demonstrar que as ideias de Popper relativas ao progresso continuam bastante atuais e encontram respaldo nas mais diversas áreas do conhecimento, contribuindo para fundamentar entendimentos acerca de questões pontuais, como, no exemplo apresentado, para o problema dos precedentes no Direito.

Palavras-chave: Popper, Verificabilidade, Falseabilidade, Progresso, Precedentes.

\begin{abstract}
The concept of gene, as proposed in the course of the twentieth century, seems to be going through one of the most interesting and complicated times by which scientific terms sometimes go through: the review of concepts and terms on which it relies. To understand this delicate - and exciting moment, we need to understand the history behind the development of the concept that is currently used in the biological sciences. For this purpose, we depart from Mendel and his solitary scientific adventure, which was only posthumously recognized for its vital contribution to the development of science, passing through the dispute of understanding the processes of heredity in the early twentieth century, the advances that allowed the passing century was called "the century of the gene" and finally reaching the progress and limits that has glimpsed after the success of the initially controversial Human Genome Project.
\end{abstract}

Key-words: Popper, Verifiability, Falsifiability, Progress, Precedents. 


\section{I-O debate acerca do empirismo lógico: O Círculo de Viena}

O ambiente intelectual de debate acerca de questões científicas que se estabeleceu em Viena nas décadas de 1920 e 1930 levou à criação de vários grupos de discussão, sendo o Círculo de Viena o mais conhecido dentre eles ${ }^{1}$. Todavia, há várias definições alternativas para designar essa corrente do pensamento filosófico: empirismo lógico, positivismo lógico ou neopositivismo. Todas essas definições apontam para o fato de que, em certo sentido, pretendeu-se retornar a uma posição clássica da história da filosofia, que diz respeito ao modo como nós adquirimos conhecimentos sobre o mundo: a posição empirista e não metafísica. No entanto, apesar do empirismo lógico enfatizar o papel da ciência na construção do conhecimento, essa nova fase defendeu um método diferente para a consecução de seus objetivos: a análise lógica da linguagem - nesse caso os enunciados científicos -, inspirada nos trabalhos de Bertrand Russell e Ludwig Wittgenstein.

Para a concepção científica do mundo defendida pelo Círculo de Viena, não há enigmas insolúveis para o intelecto humano, mas tudo é acessível ao homem. Contudo, não se admitem conhecimentos válidos a priori, como os juízos sintéticos a priori de Kant. Tal ênfase na ciência fez com que o Círculo recusasse qualquer forma de metafísica, chegando mesmo a defender que a filosofia não existe como uma disciplina equiparada às ciências, com proposições próprias, uma vez que, para os positivistas lógicos, o conjunto de proposições científicas é a totalidade dos enunciados dotados de sentido. Para esses pensadores, a tarefa do trabalho científico é justamente esclarecer os problemas filosóficos tradicionais, para que estes sejam revelados como pseudoproblemas ${ }^{2}$ e, na medida do possível, transformados em problemas empíricos. Um dos principais objetivos do Círculo era a unificação das ciências.

\footnotetext{
${ }^{1}$ O Círculo-Schlick, que ficou conhecido como "Círculo de Viena", não foi o único grupo que ocupou-se em discutir tópicos relativos ao conhecimento humano (filosofia, economia, etc.). Além desse grupo presidido por Schlick, existiram vários outros, como, por exemplo, aquele que posteriormente foi chamado de "Primeiro Círculo de Viena" (1907 - 1912), que tratou de temas epistemológicos. Deste último participaram o físico Philipp Frank, o matemático Hans Hahn, e o sociólogo Otto Neurath, pensadores que também integraram o Círculo-Schlick. Hahn e Neurath foram, inclusive, signatários do texto que é considerado o Manifesto do Círculo de Viena, intitulado A concepção científica do mundo - O Círculo de Viena (GOMES, 2011, p.846-847, 850).

2 Trata-se de problemas relativos a pseudofatos (fatos inexistentes tomados equivocadamente como fatos), suscitados por ideias difusas ou por falhas no conhecimento. Um exemplo do primeiro tipo é a pergunta "Como funciona a levitação?". Para o segundo tipo, de um problema gerado por uma ideia difusa, temos: "Por que existe algo em vez de não existir nada?". Quanto ao terceiro tipo, temos, por exemplo, os paradoxos do corvo e das esmeraldas verzuis (BUNGE, 2006, p.316).
} 
Fizeram parte do Círculo de Viena pensadores como Moritz Schlick, Hans Hahn, Phillipp Frank, Otto Neurath, dentre outros. Contudo, um dos principais expoentes da orientação filosófica do Círculo foi o pensador alemão Rudolf Carnap, que foi o responsável por uma das principais contribuições para a teoria da construção científica do mundo: a formulação do princípio da verificabilidade.

Para os positivistas lógicos, incluindo Carnap, o princípio da verificabilidade é condição necessária para estabelecer uma linguagem significativa (liberta dos erros causados por um mau uso da linguagem) e intersubjetiva, que por sua vez irá possibilitar o êxito do projeto de unificação das ciências. De acordo com a concepção do Círculo, a condição para o estabelecimento do conhecimento científico reside nas proposições verdadeiras ou bem estabelecidas. Devemos ser capazes de dizer se determinada proposição é verdadeira ou falsa, e isso só é possível se pudermos verificar tal enunciado. Um enunciado só é dotado de sentido na medida em que pode ser verificado, e dessa forma, se pretendemos saber o que alguém diz, devemos perguntar: "Como você verifica esse enunciado?” Apenas se o interlocutor for capaz de responder a essa pergunta, demonstrando o que pretendeu dizer (e não meramente buscando explicar o significado das suas palavras), o enunciado será dotado de sentido.

Por esse motivo, da obrigatoriedade da verificação do enunciado, a metafísica é considerada sem sentido, uma vez que não satisfaz o critério empirista do significado (da verificação) $)^{3}$. O método da análise lógica da linguagem estabelece que os enunciados metafísicos são absurdos porque neles ocorrem palavras sem sentido empírico (impossíveis de serem verificadas, como, por exemplo, o "absoluto", o "nada", etc.), ou porque as palavras foram combinadas contra as regras da sintaxe lógica (BASTOS, 2008, p.61-63).

\section{II - Karl Popper: crítico do princípio de verificabilidade}

Karl Popper foi um dos mais contundentes críticos da concepção científica do mundo desenvolvida pelo Círculo de Viena. Sua crítica perpassa por vários alicerces do pensamento dos positivistas lógicos. Logo no início de A lógica da pesquisa científica ${ }^{4}$ (p.34-35), Popper

\footnotetext{
${ }^{3}$ Principalmente durante a primeira formulação do princípio da verificabilidade, ocasião em que o ataque à metafísica, visando destrui-la, foi um dos temas preferidos de Carnap (BASTOS, 2008, p.61).

${ }^{4}$ A obra foi publicada originalmente em 1934, em alemão, com o título Logik der Forschung. A tradução em português utilizada para a redação deste artigo é de 1975.
} 
rejeita o método indutivo, porque, segundo o filósofo, a lógica indutiva não contribui para estabelecer um critério de demarcação adequado. Para Popper, o problema da indução e o da demarcação consistem na fonte de quase todos os outros problemas da teoria do conhecimento, embora defenda que o da demarcação é ainda mais importante. Popper denomina por problema de demarcação o estabelecimento de um critério que permita distinguir entre as ciências empíricas, a Matemática e a Lógica, de um lado, e as questões metafísicas de outro.

Partindo dessa ideia de um critério de demarcação para delimitar a ciência e o que não é ciência, Popper critica o princípio de verificabilidade defendido pelos positivistas lógicos como o método para determinar se um enunciado é dotado de sentido e, portanto, científico 5 . Para Popper, não se trata de um bom critério para separar a ciência da metafísica, pois o autor defende que esta não é completamente carente de sentido, mesmo não sendo uma ciência. Assim, a demarcação entre enunciados científicos dotados de sentido, de um lado; e enunciados pseudocientíficos ou metafísicos, carentes de sentido, de outro, é algo que não se sustenta.

Uma das formas mais aceitas para contrapor ciência e metafísica é dizer que a primeira é caracterizada por sua base na observação e por seu método indutivo, enquanto que a pseudociência e metafísica distinguem-se por sua ênfase no método especulativo. Contudo, esse modo de separar ciência e metafísica encontra sérios problemas: de um lado, enunciados científicos como a teoria da relatividade e a física quântica estão muito distantes do âmbito observacional, pautando-se em postulados e princípios bastante abstratos e especulativos (BASTOS, 2008, p.85); e, no extremo oposto, crenças supersticiosas populares, como as previsões astrológicas, baseiam-se em dados observacionais, da experiência cotidiana das pessoas, e nem por isso podem ser consideradas teorias científicas.

Na concepção popperiana, expressa em A lógica da pesquisa científica, inferências que conduzem a teorias, a partir de enunciados verificados por meio da experiência, são logicamente inadmissíveis. Ou seja, trata-se de uma clara rejeição do método indutivo nas ciências e, dessa forma, Popper evita a contradição exposta acima, em que crenças populares baseadas na observação poderiam levar, por meio de inferências indutivas, a uma conclusão

\footnotetext{
${ }^{5} \mathrm{Na}$ visão dos positivistas lógicos, um enunciado dotado de sentido é um enunciado científico.
} 
fundada nesses dados observacionais, mas que, contudo, não poderia ser considerada uma proposição científica.

Por outro lado, Popper defende que as teorias nunca podem ser empiricamente verificáveis (POPPER, 1975, p.41-42). Com essa assertiva, o filósofo contorna o paradoxo que identificou nas ideias dos positivistas lógicos, pois se a tese desses últimos for aceita, a saber, que o critério de demarcação entre ciência e metafísica consiste no método de verificação, as leis científicas universais, apesar de extremamente importantes para o desenvolvimento da ciência, seriam excluídas do escopo das proposições científicas, por não serem passíveis de verificação. Atento a essa contradição no sistema teórico dos positivistas lógicos, Popper propõe o estabelecimento de um novo critério de demarcação, que possibilite incluir, no âmbito da ciência empírica, enunciados impossíveis de verificação (a saber, as leis científicas universais).

No entanto, Popper admite que só reconhece um sistema como científico na medida em que ele é passível de comprovação pela experiência ${ }^{6}$ (POPPER, 1975, p.42). Em um primeiro momento, isso parece contradizer a convicção popperiana de que as teorias não podem ser verificadas empiricamente, afinal o filósofo afirma que um sistema é passível de comprovação empírica. Contudo, a particularidade de Popper reside no fato de que, apesar de não ver problemas em corroborar teorias por meio da experiência, considera que tal corroboração consiste na tentativa de falsificar essas teorias por meio de testes, ao invés de verificá-las, conforme defendiam os empiristas lógicos. Ou seja, essa "comprovação pela experiência" caminha em direção oposta: as teorias são "comprovadas" enquanto conseguem resistir às sucessivas tentativas de refutação. Trata-se, na verdade, de uma mudança de critério de demarcação. Popper defende a falseabilidade como um critério mais adequado para definir os limites da ciência. Em vez de defender a validação de um sistema científico em sentido positivo (à maneira dos empiristas lógicos), Popper aposta na validação de um sistema a partir de um ponto de vista negativo, ou seja, tentando refutar esse sistema através de provas empíricas, ao invés de confirmá-lo ${ }^{7}$. Esse é um ponto central da crítica de Popper à concepção científica do Círculo, sendo que tal requisito negativo, o da falseabilidade ou refutabilidade,

\footnotetext{
${ }^{6}$ Trata-se de um ponto polêmico na filosofia de Popper. Afinal, essa "comprovação pela experiência" não consiste em tornar um sistema científico definitivamente válido, mas sim a possibilidade de refutar esse sistema por meio da experiência (POPPER, 1975, p.42).

${ }^{7}$ Conforme exposto em A lógica da pesquisa científica, página 42.
} 
também exerce influência fundamental nas reflexões do autor acerca do progresso na ciência, que será discutido adiante.

\section{III - Progresso na ciência na concepção de Popper}

Popper discute a questão do progresso na ciência em uma conferência intitulada $A$ Racionalidade das Revoluções Científicas (POPPER, 2004, p.50-84), que foi dividida em duas partes: na primeira (seções I a VIII), o autor discute a questão do progresso de modo mais específico, enquanto que na segunda parte (seções IX a XIV), ele problematiza questões decorrentes do progresso científico, que são os obstáculos sociais para sua consecução. $\mathrm{O}$ presente artigo limita-se a discutir apenas como Popper apresenta a questão do progresso, que será exposta a seguir.

Logo no início de sua conferência ${ }^{8}$, Popper salienta que discutirá a questão do progresso a partir de um ponto de vista da seleção natural, ou seja, a partir de uma tendência biológica. Contudo, o autor não sugere que tal abordagem seja a mais importante para a discussão acerca do progresso da ciência, mas justifica sua escolha pela orientação biológica porque reconhece que esta é conveniente para introduzir as duas ideias fundamentais para a análise que pretende desenvolver: as ideias de instrução e de seleção. Segundo Popper, a ciência, ou o progresso na ciência, pode ser considerado como um instrumento utilizado pela espécie humana para se adaptar ao ambiente ${ }^{9}$. A partir dessa consideração, o autor apresenta três níveis de adaptação distintos: adaptação genética, aprendizagem do comportamento adaptável e a descoberta científica (sendo esta última um caso especial de aprendizagem do comportamento adaptável), discutindo o papel desempenhado pela instrução e seleção em cada nível (POPPER, 2004, p.51-52).

\footnotetext{
${ }^{8}$ A partir deste ponto, refiro-me ao texto A Racionalidade das Revoluções Científicas (POPPER, 2004, p.50-84).

${ }^{9}$ Popper não distingue claramente as noções de adaptação e progresso, pois embora tenha sugerido que o progresso consiste em um instrumento para a adaptação humana ao ambiente, logo em seguida, ao distinguir os três níveis de adaptação, utiliza os termos indistintamente, sugerindo que tais noções possam ser substituídas uma pela outra, conforme pode ser percebido no seguinte trecho: "Meu maior problema nesta parte da minha alocução será investigar as semelhanças e diferenças entre as estratégias de progresso ou adaptação ao nível científico e àqueles dois outros níveis" (POPPER, 2004, p.52).
} 
A tese de Popper é de que, nos três níveis, o mecanismo de adaptação é o mesmo. Para fundamentar sua assertiva, o autor explica que a adaptação começa a partir de uma estrutura herdada que é básica para todos os níveis: a estrutura genética do organismo, a qual corresponde, no nível do comportamento, o repertório inato de comportamentos disponíveis ao organismo, e no nível cientifico, as teorias científicas dominantes. De acordo com Popper, todas essas estruturas são transmitidas pela instrução, que por sua vez, nas palavras do autor, vem de dentro da estrutura, e não do ambiente externo. No caso dos níveis genético e de comportamento, a estrutura é repassada por meio da réplica da instrução genética codificada, enquanto que no nível científico, e também do comportamento, a transmissão é feita através da imitação e tradição social (POPPER, 2004, p.52).

Tais estruturas herdadas podem ser expostas a pressões de seleção, desafios ambientais ou problemas teóricos. Quando isso ocorre, são produzidas variações das instruções herdadas, genética ou tradicionalmente, e da mesma forma como ocorre com a instrução, as variações são mudanças oriundas de dentro da estrutura. No nível genético, tais variações consistem em mutações e recombinações da instrução codificada; no nível comportamental, são recombinações experimentais por entre o repertório; e no nível científico, trata-se de teorias experimentais revolucionárias. Após essa fase, há o estágio da seleção das variações disponíveis, que é o estágio da eliminação do erro. Nesse estágio, apenas as instruções mais ou menos bem adaptadas sobrevivem e são transmitidas futuramente. Esse processo de eliminação do erro, ou de instruções mal adaptadas, é denominado por Popper como um processo de seleção natural, que ocorre nos três níveis de adaptação.

Após delinear o processo pelo qual variações são produzidas, como uma tentativa de solucionar problemas gerados pelas instruções herdadas, e como se dá a sua posterior seleção natural, Popper exemplifica alguns tipos de mudanças (variações) que podem ocorrer: ele cita, por exemplo, a mutação de um gênero no nível genético, e consequentemente a mudança de uma enzima, que por sua vez propiciará alterações na cadeia de enzimas, que poderá ocasionar "novas relações entre o organismo e o mais remoto meio ambiente" (POPPER, 2004, p.54), além de novas pressões seletivas.

O filósofo também discute a natureza dessas transformações no nível científico ${ }^{10}$, em que a adoção de uma nova teoria pode solucionar problemas, mas que, contudo, ocasiona

\footnotetext{
${ }^{10}$ A tradução utilizada menciona "nível de comportamento", ao invés de "nível científico". Porém, o texto subsequente à expressão trata das transformações em nível científico, conforme sugere o seguinte trecho: "a adoção experimental de uma nova conjectura ou teoria pode solucionar um ou dois problemas, mas isto introduz,
} 
invariavelmente muitos problemas novos, pois, segundo Popper, uma teoria revolucionária funciona "como um novo e poderoso órgão sensitivo" (POPPER, 2004, p.54). Ou seja, na concepção de Popper, uma nova teoria tem a capacidade de perceber novos problemas que não foram notados pela teoria predecessora. Se houver progresso efetivamente, os novos problemas estarão em um nível de profundidade muito diferente do que os problemas anteriores, e nisso residirá a diferença entre eles. Popper cita algumas teorias que originaram problemas inesperados, mencionando a relatividade, a mecânica quantitativa e a biologia molecular (POPPER, 2004, p.54).

Acerca do exposto acima, no decorrer do tópico III deste artigo, torna-se claro como Popper se apropriou da linguagem da biologia e da evolução para desenvolver as suas reflexões sobre o progresso na ciência. De modo bastante claro, o próprio autor admite, logo em seguida à sua exposição sobre a natureza das variações em nível científico, que esta é forma pela qual ele acredita que a ciência progride. Tal progresso, assevera Popper, pode ser mais bem avaliado se compararmos nossos velhos problemas com os novos. Isso porque os problemas novos serão mais profundos, e em maior número. Para Popper, quanto maior for o progresso em conhecimento, melhor poderemos discernir o tamanho da nossa ignorância (POPPER, 2004, p.54).

Mais adiante, de modo bastante sucinto, Popper define a sua noção de progresso na ciência, ou de descoberta científica, afirmando que esta depende da instrução (como um elemento conservador, que conforme foi esclarecido acima, é a maneira pela qual as estruturas são transmitidas) e da seleção (que consiste no uso da experimentação e eliminação de erro, por meio de testes e exames empíricos, com o intuito de expor as fraquezas das teorias e tentar refutá-las). Assim, Popper ressalta mais uma vez o seu compromisso com o ponto de vista da seleção natural para discutir a questão do progresso, o que possibilita entender porque o filósofo escolheu utilizar esse tipo de abordagem.

Logo na apresentação da estrutura de sua conferência, Popper ressaltou que iria discutir amplamente o progresso na ciência de um ponto de vista revolucionário, ou mais especificamente, de um ponto de vista da seleção natural, orientação que foi exposta até o momento neste artigo. Contudo, Popper já havia advertido que também discutiria a questão do

invariavelmente, muitos problemas novos, pois uma nova teoria revolucionária funciona exatamente como um novo e poderoso órgão sensitivo" (POPPER, 2004, p.54). 
progresso de um ponto de vista lógico, para a qual o filósofo dedica a seção VIII da conferência (POPPER, 2004, p.67-70). Embora a maior parte do debate tenha se desenvolvido no âmbito da biologia, a adoção dos critérios racionais ou lógicos é de fundamental importância para a proposta popperiana de progresso científico, consistindo no cerne das considerações críticas do autor acerca do assunto em pauta.

Assim, do ponto de vista lógico, Popper propõe dois critérios racionais para o progresso na ciência. Primeiramente, o autor estabelece que uma teoria seja considerada como um passo adiante em relação às outras se essa nova teoria conflitar com a sua antecessora, ou seja, se apresentar alguns resultados contraditórios. Isso significa que a nova teoria deve contradizer a sua predecessora, derrotá-la nesse sentido. Sob essa perspectiva, o progresso na ciência é sempre revolucionário. Não obstante, o progresso na ciência também é, em certa medida, conservador, pois mesmo sendo revolucionária, a nova teoria sempre deve ser capaz de explicar, completamente, o sucesso de sua antecessora. Em todos os casos em que a teoria antiga foi bem sucedida, a nova teoria deve apresentar resultados igualmente bons e, se possível, ainda melhores do que os resultados alcançados pela teoria predecessora. Em tais casos, a teoria antiga deve parecer uma boa aproximação à teoria nova, mas deve haver ocasiões em que esta última produza resultados melhores e diferentes daqueles conquistados pela teoria anterior.

De acordo com Popper, os critérios lógicos apresentados são importantes porque eles permitem decidir acerca de qualquer teoria nova, antes mesmo de ela ter sido testada, se ela será melhor do que a predecessora, desde que se submeta a testes. Trata-se, portanto, de um critério para avaliar a qualidade de uma teoria se comparada com a sua antecessora, consistindo assim em um critério de progresso. Para Popper, isso significa que o progresso na ciência é passível de avaliação racional.

IV - Aplicação prática da noção de progresso popperiana: a questão dos precedentes no Direito

A aplicação prática das reflexões popperianas acerca do progresso não está restrita às ciências naturais ou mesmo à filosofia. $\mathrm{O}$ alcance das ideias desenvolvidas por Popper não é limitado à época ou contexto em que o filósofo escreveu, e nem mesmo a áreas específicas do conhecimento. Um exemplo a esse respeito, que mostra que as ideias de Popper continuam 
sendo estudadas e debatidas, é o recente artigo de Adriana Wyzykowski (2012), que propõe uma aplicação concreta do método popperiano ao desenvolvimento de um sistema de precedentes no Direito. Após empreender uma reconstrução do pensamento de Popper, passando pelas reflexões do autor a respeito do progresso científico, Wyzykowski inicia a discussão acerca do tema central de seu artigo, ao apresentar a noção de precedentes nas ciências jurídicas.

Primeiramente, a autora expõe a noção de precedentes como sendo regras gerais estabelecidas por juízes a partir de determinados casos que, posteriormente, são utilizadas para embasar decisões acerca de outras situações semelhantes. Considerando que a lei pode ser interpretada de diversos modos, e que casos iguais podem ser tratados de maneiras completamente diferentes por determinados juízes, a igualdade nas decisões judiciais conduziria à segurança jurídica. Esta, por sua vez, poderia ser obtida mediante a adoção de um sistema de precedentes, que proporcionaria a estabilidade e continuidade da ordem jurídica, com a consequente previsibilidade dos desdobramentos jurídicos de determinada conduta.

Contudo, apesar do sistema de precedentes contribuir para superar a desigualdade ocasionada por julgamentos contraditórios entre si (por versarem sobre casos semelhantes), tal sistema não possui apenas características positivas. Segundo Wyzykowski, a principal crítica direcionada aos precedentes consiste na acusação de que eles poderiam levar a uma estagnação do Direito. Isso porque, na medida em que determinado precedente é aplicado, a discussão acerca do caso, ou a interpretação da discussão, torna-se engessada, estagnando assim a jurisprudência e a doutrina jurídica. Porém, essa crítica à utilização dos precedentes só é consistente caso implique que os precedentes jamais possam ser modificados.

Wyzykowski articula a sua argumentação de modo a responder de modo satisfatório à acusação de engessamento do Direito como consequência direta do uso de precedentes. A autora defende que os precedentes podem ser modificados ou superados para que possam acompanhar a evolução do ordenamento jurídico, observando a modificação dos fatos, valores e normas, além da evolução doutrinária de determinado sistema. O processo de superação ou modificação do precedente, denominado overruling, faz com que o precedente perca a sua eficácia, em virtude da adoção de um novo valor interpretativo para o caso em que o antigo precedente era o paradigma. Contudo, a superação de um precedente é resultado de um longo 
processo de modificação da concepção moral, social, política ou teórica do sistema jurídico em determinada sociedade, acompanhando, portanto, a evolução da própria comunidade em questão.

A tese da autora é que o método de superação de um precedente é reflexo do método popperiano. Da mesma forma em que uma teoria científica pode ser válida em determinado momento, um precedente pode representar uma solução adequada em um determinado período. Isso não significa, porém, que tanto a teoria científica quanto o precedente não possam ser discutidos posteriormente, sendo até mesmo plausível que sejam refutados. De modo análogo a uma teoria, um precedente pode ser exposto a determinadas pressões, modificações sociais ocorridas no interior da sociedade que, para Popper, constituem-se em pressões ou problemas capazes de gerar novas teorias.

Após o aparecimento de teorias experimentais ou novos precedentes, ambos serão expostos à crítica, etapa que Popper denomina seleção natural. Nessa fase, haverá a eliminação de erros e fragilidades das teorias científicas ou de precedentes novos, onde, no caso dos precedentes, eles serão submetidos ao arbítrio dos magistrados para que possam ser experimentados e refutados. Ao fim desse processo, um novo precedente é criado para atender às modificações sociais e para evitar a estagnação do Direito, da mesma forma em que uma nova teoria passa a ser adotada por determinada comunidade científica.

Contudo, analogamente ao segundo critério lógico exposto por Popper para explicar o progresso científico, em que uma teoria revolucionária deve ser completamente capaz de explicar o sucesso da teoria predecessora, o novo precedente deve ser capaz de apontar o sucesso de seu antecessor durante o período de vigência deste, apresentando ao mesmo tempo as razões pelas quais representa um progresso em comparação com o precedente anterior, motivos pelos quais este é vencido pelo novo precedente.

$V-$ Conclusão

Este estudo acerca da noção de progresso em Karl Popper permitiu retomar a discussão a respeito das divergências intelectuais entre esse filósofo e os seus contemporâneos do Círculo de Viena, afinal a questão do progresso científico está intimamente relacionada ao princípio da falseabilidade. Mostrou-se que enquanto uma teoria ainda consegue resistir a testes, a pressões ou desafios (enquanto não é refutada), ela continua em vigor, mesmo tendo 
de se submeter a determinadas variações para prosseguir como uma teoria válida. Pode haver progresso científico quando são produzidas variações para salvar a teoria principal, ou mesmo quando a teoria precisa ser completamente substituída, caso em que foi falseada. Nota-se, portanto, a estreita relação entre progresso e falseabilidade: uma teoria refutada proporciona progresso na medida em que é substituída por uma nova teoria capaz de produzir resultados melhores do que a sua predecessora.

Assim, é possível perceber que a argumentação de Popper segue uma direção unívoca, de considerar que a validação de um sistema científico deve ser feita de forma negativa: em vez de comprovar que algo é válido, deve-se reunir esforços para provar que tal sistema, até determinado momento, ainda não pode ser invalidado. Logo, não se trata de tentativas de afirmar uma teoria científica, mas de um esforço para refutá-la, justamente para testar a sua resistência. Tendo a teoria da evolução como referência, parece ser possível afirmar que Popper propõe uma lógica do progresso científico. Essa lógica tem-se se mostrado útil em domínios outros que as ciências naturais, como vimos.

\section{Referências bibliográficas}

BASTOS, Cleverson Leite; CANDIOTTO, Kleber B.B. Filosofia da ciência. Petrópolis: Vozes, 2008.

BUNGE, Mario. Dicionário de filosofia. Tradução de Gita K. Guinsburg. $1^{\text {a }}$ ed. São Paulo: Perspectiva, 2006 (Coleção Big Bang).

GOMES, Nelson. Os Progressos da Filosofia no Século XX, in Samuel Simon (org.) Um Século de Conhecimento: Arte, Filosofia, Ciência e Tecnologia no século XX. Brasília: Editora Universidade de Brasília, 2011, p.795-871.

POPPER, Karl Raimund. A lógica da pesquisa científica. São Paulo: Cultrix, 1975.

Lógica das Ciências Sociais. $3^{\text {a }}$ ed. Rio de Janeiro: Tempo Brasileiro, 2004 (Biblioteca Tempo Universitário $\mathrm{n}^{\circ} 50$ ).

WYZYKOWSKI, Adriana. O overruling como aplicação concreta do método popperiano ao desenvolvimento de um sistema de precedentes. Revista do Curso de Direito da UNIFACS, $\mathrm{n}^{\circ} 149,2012$. 